\title{
PAULLINIA CEARENSIS (SAPINDACEAE) NUEVA ESPECIE DE BRASIL
}

\author{
por GENISE V. SOMNER ${ }^{1}$ y MARIA S. FERRUCCI ${ }^{2}$
}

\begin{abstract}
Summary
Somner \& Ferrucci (Sapindaceae-Paullinieae) from The new species Paullinia cearensis Somner \& Ferrucci (Sapindaceae-Paulliniea
northeastern Brazil is described, illustrated, and compared to its closest relatives.
\end{abstract}

El género Paullinia comprende aproximadamente 200 especies americanas, a excepción de $P$. pinnata L. que también vive en Africa tropical. Se reconoce fácilmente dentro de la tribu Pauilinieae por sus vistosas cápsulas rojas o amarillas y sus semillas generalmente provistas de un arilo blanco que contrasta con el tegumento castaño-oscuro; en el material florífero un buen carácter para reconocer el género está dado por los granos de polen oblatos, raro peroblatos, isopolares y triporados.

La posibilidad de estudiar la colección de Sapindáceas depositadas en el Herbario Prisco Bezerra, nos permite describir una especie de Brasil, que consideramos nueva para la ciencia.

\section{Paullinia cearensis Somner \& Ferrucci} nov. sp.

Fig. 1

Frutex scandens, rami juniores, foliae et inflorescentiae axes indumento flavido ad ferrugineo induto. Caulis 3 costatis, corpo lignoso simplice. Stipulac subulatae, deciduae, 4-8 $\mathrm{mm}$ longae, sericeae. Folia composita, imparipinnata, bijuga. Petiolus et rhachis ventraliter canaliculati; foliolis subcoriaceis, cllipticis, oblongis, ovato-angustis, margine dentatoserrato, supra et infra glabriusculis, glandulis geniculatis obsita. Thyrsi axillares et thyrsi duplices terminales, cincinnis sessilibus, bracteis subulatis. Flores 4,5-5,5 $\mathrm{mm}$ longae. Sepala 5, exteriora 2, interiora

${ }^{1}$ Profesora del Area de Botánica, Universidade Federal Rural do Rio de Janeiro, Seropédica, RJ, Brasil, 23851-970.

${ }^{2}$ Miembro de la Carrera del Investigador Científico y Tecnológico, CONICET. Instituto de Botánica del Nordeste (UNNE-CONICET). C.C. 209, 3400 Corrientes, Argentina.
3, ille 2 inferioris ima basi coalitis. Capsula septifraga, coriacea, ellipsoidea, 6-costata, uniseminata, apiculata, 12,5-14,5 mm longa, 8-9 mm lata, stipite incluso, 1,3-8 $\mathrm{mm}$ longo; extus puberillo, intius lanata. Semeri ellipsoideum, arillatun.

Holotipo: BRASIL. Ceará. Na entrada de Piçarra para Viçosa do Ceará, fruto vermelho, carrasco, 22-II-1979 (fr), Fernandes, A. et A.J. Castro s.n. (EAC 5639). Isotipo: CTES.

Frútices trepadores, monoicos, con flores pseudoperfectas funcionalmente pistiladas $\mathrm{y}$ flores estaminadas. Indumento de pelos crespos, amarillento a ferrugíneo en tallos jóvenes, ejes de las hojas e inflorescencias. Rama florífera castaño-oscura, 3-5 mm diám., con 3 costillas redondeadas; luego terete, glabra, con lenticelas castaño-claras; cámbium único. Estípulas subuladas, caducas, 4-8 mm long., seríceas; pecíolo canaliculado ventralmente, 1,3-9 cm long., pubescente sólo en el canal; lámina pinnaticompuesta, 5-foliolada; raquis bicanaliculado, generalmente de menor longitud que el pecíolo, 14-32 mm long., pubescente; folíolos peciolulados a subsésiles, subcoriáceos, elípticos, oblongos u ovado-angostos, oliváceos generalmente con epifilo más oscuro, 5-12,7 x 1,5-5,5 cm, base del folíolo terminal aguda, obtusa en los demás, ápice agudo, a veces retuso, margen dentadoserrado, 7-16 dientes obtusos en los 2/3-1/2 distal, glandulares; epifilo y a veces el hipofilo con vena media y secundarias pubérulas. hipofilo con venación reticulada prominente, axilas barbadas, ambas caras con pelos glandulares geniculados. Tirso espiciforme, axilar 


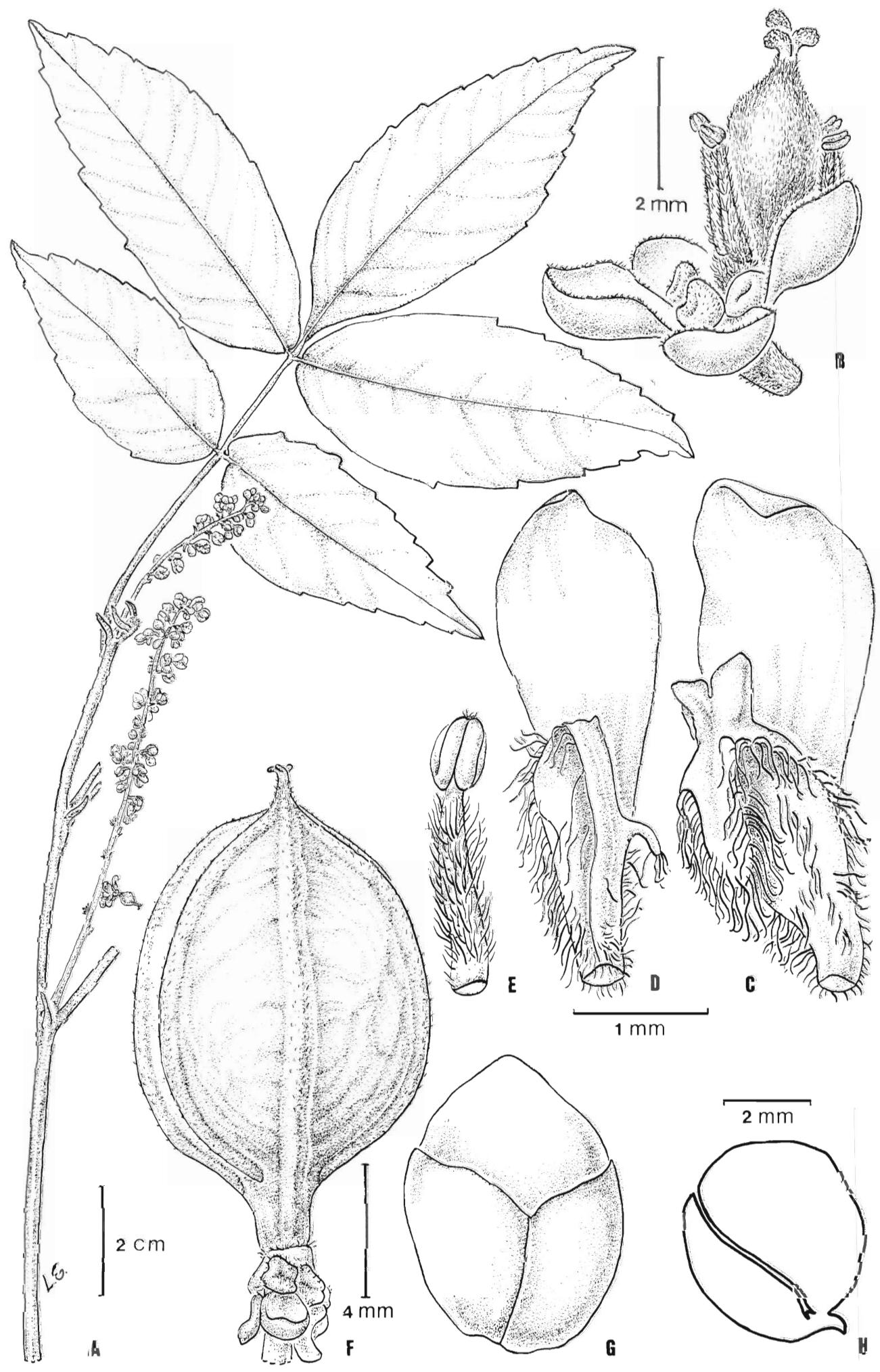

Fig. 1. Paullinia cearensis. A, rama florífera; B, flor pistilada desprovista de pétalos, mostrando los nectarios; C, pétalo superior, cara interna; D, petalo lateral, cara interna; E, estambre de la flor pistilada (Figueiredo s.n., CTES); F, fruto poco antes de la dehiscencia; G, semilla, vista dorsal (Fernandes et Castro s.n., isotipo); H, embrión, corte longitudinal (Fernandes et Castro s.n., holotipo). 
o tirso doble terminal, pedúnculo de sección cuadrangular a subterete, 0,5-9 cm long., ecirroso o con 2 zarcillos en la base del raquis, este último anguloso, 24-103 mm long., cincinos sésiles, 3-6-floros; pedicelo floral 1,5$3,5 \mathrm{~mm}$ long., en el fruto hasta 3,5 mm long., articulado en la base o algo por debajo de la mitad; brácteas subuladas, 1,5-2 mm long., pubescentes, bractéolas conformes, menores. Flores 4,5-5,5 mm long. Sépalos 5, 2 externos ovados, 1,5 x 1,5-1,75 mm; los internos oblongos, 2,5 x 1,75 mm, los inferiores soldados en la base; todos con pelos crespos en la cara abaxial. Pétalos oblanceolados, unguiculados, 3,75-4 x 1,2-1,5 mm, ambas caras glandulosas; escama de los pétalos superiores con la cresta emarginada. Nectarios 4, ovoides, los 2 superiores obtusos, los laterales agudos; pubescentes. Androginóforo y andróforo pubescentes. Estambres 3-4 mm long. en la flor estaminada, en la flor pistilada 2-3 mm long.; en ambos filamentos vellosos, anteras pubérulas. Pistilodio velloso. Ovario ovoide, seríceo, estilo piloso, igual o más largo que las ramas del estigma. Cápsulas rojas, septífragas, elipsoidales, 6-costatas, coriáceas, uniseminadas, apiculadas, $12,5-14,5 \times 8-9 \mathrm{~mm}$, incluido el estípite de 1,3-8 mm long.; epicarpo rugoso, pubérulo; endocarpo lanoso, pelos largos, acintados, castaño-claros. Semillas elipsoidales, 8-9,5 x 5,5-6,7 mm; arilo de $\pm 1 / 2$ del largo de la semilla, hendido en dos lóbulos. Embrión esferoidal, oblicuo; radícula corta, alojada en un repliegue del tegumento; cotiledones amiláceos, crasos.

Paratipos. BRASIL. Ceará. S.d., (fr), Löfgren, A. 238 (R); Municipio Novo Oriente, Planalto Ibiapaba, alt. 760 m, 10-VII-1990 (fr), Araúijo 109 (EAC); Baixa Fria, Pl. Ibiapaba, 5-I-1991 (fr), Araújo 237 (EAC); Bom Jesus, Alcântara, Serra da Meruoca, 3-I-1976 (fl), Fernandes s.n. (CTES,EAC 2681); Meruoca, Sítio Santo Antônio, 25-II-1981 (fl,fr), Fernandes ct Martins s.n. (EAC 9750); Serra do Vicente, Capistrano, 18-X-1979 (fl), Figueiredo s.n. (CTES,EAC 7144,RBR); Serra da Ibiapaba, Guaraciaba do Norte, 18-XII-1979 (fl,fr), Martins et Nunes s.n. EAC 7836 (CTES); Estrada Reriutaba a Guaraciaba do Norte, 24-XII-1980 (fr), Martins s.n. (CTES, EAC 9557); Corginho, São Benedito, Serra da Ibiapaba, à margem de uma estrada, 5-I-1942 (fl,fr), Prisco Bezerra s.n. (EAC 436); Cuita, São Benedito, Serra da Ibiapaba, 6-I-1942 (fl,fr), Prisco
Bezerra s.n. (EAC 461). Piauí. Mun. Pedro II, Serra dos Motões, a mais ou menos $810 \mathrm{~m}$ de altitude, 24-VI-1972 (fr), Sucre et Silva 9297 (CTES,RB).

Nombre vernacular: «mata fome».

Distribución geográfica y hábitat. Vive en el NE de Brasil, en los estados de Ceará y Piauí, donde ha sido coleccionada entre junio y febrero en diferentes ambientes como cerrado, carrasco o capoeira.

Nota. Dentro de las trece secciones propuestas para el género (Radlkofer, 1931-1932), P. cearensis pertenece a la sección Pleurotoechus Radlk. cuyas especies tienen en común el pericarpio poco engrosado con 3 ó 6 costillas longitudinales y el cáliz dialisépalo, o raro con los dos sépalos inferiores soldados en la base hasta la mitad.

Entre sus congéneres las más afines serían P. subcordata Benth., conocida para Brasil, Amazonas y P. costata Schldtl. et Cham., citada para México y América Central (Radlkofer, 1931-1932). Ambas especies presentan los folíolos enteros con las venas terciarias percurrentes notables y el epicarpo densamente pubescente, caracteres que permiten diferenciarla fácilmente de $P$. cearensis. $P$. subcordata se distingue además por el hipofilo pubescente y las estípulas obovado-elípticas; mientras que $P$. costata se diferencia por sus estípulas triangulares breves y por el embrión con los cotiledones plegado-curvados y oleosos.

\section{Agradecimientos}

Las autoras agradecen al personal del Herbario Prisco Bezerra por haber puesto gentilmente a disposición el material de la institución; a la. Sra. L. Gómez por la confección de la lámina y al Ing. Agr. C. Zanín por la corrección de la diagnosis. Para la realización de este trabajo la segunda autora contó con el apoyo económico de la SECYT-UNNE y el subsidio \# 5343-94 de la National Geographic Society.

\section{Bibliografía}

Radlkofer, L. 1931-1932. Sapindaceae, in Engler, Pflanzenr. 4. 165: 219-352, f. 5-6. 